Artículos

\title{
Posicionar la investigación de borde
}

Edge search position

Silvia Valiente

DOI: https://doi.org/10.24215/18537863e072

Centro de Investigación y Transferencia de CONICET

Catamarca, Universidad Nacional de Catamarca

(CITCA/CONICET/UNCA), Argentina

scvaliente@gmail.com

Recepción: 09 Marzo 2019

Aprobación: 06 Febrero 2020

\section{Resumen:}

Este artículo recupera algunas de las producciones del historiador y educador popular colombiano Alfonso Torres Carrillo realizadas en los últimos diez años, precursor de la denominada propuesta investigación de borde, opción teórico-metodológica y ético-política. Con la pretensión de posicionar esta propuesta, a la vez que vincular su aporte con pensadores contemporáneos de la región, aspiro desde este trabajo a contribuir a la difusión de las metodologías críticas cualitativas, dialógicas y participativas caracterizadas por la centralidad en el sujeto y la subjetividad, el desplazamiento de la objetividad hacia la reflexividad y la solidaridad en los procesos colectivos de construcción del conocimiento.

Palabras Clave: Metodologías críticas, Reflexividad, Sujeto, Subjetividad, Procesos colectivos de construcción del conocimiento.

\section{Abstract:}

This article recovers some of the productions of the Colombian historian and popular educator Alfonso Torres Carrillo made in the last ten, precursor of the so-called edge research proposal, theoretical-methodological and ethical-political option. With the aim of positioning this proposal, while linking its contribution with contemporary thinkers in the region, I hope from this work to contribute to the dissemination of qualitative, dialogical and participatory critical methodologies characterized by centrality in the subject and subjectivity, the displacement of objectivity towards reflexivity and solidarity in collective processes of knowledge construction.

KEYWORDS: Critical methodologies, Reflexivity, Subject, Subjectivity, Collective processes of knowledge construction.

\section{INTRODUCCIÓN}

(...) ¿Cómo estamos relatando el mundo en este presente histórico? ¿De qué modo somos testimonio de una época, de una generación? ¿Con cuáles claves de lectura comprendemos las realidades sociales, el mundo de hoy? ¿Cuáles son los conceptos organizadores, las categorías emergentes de las teorías producidas y por producir en el sur? (Guarín Jurado, 2017, p. 30).

Inicio este escrito con estas preguntas del profesor de la Universidad de Manizales y miembro del Grupo de Trabajo Clacso "Ciencias Sociales: Tendencias, perspectivas y desafíos” Germán Guarín Jurado, quien nos invita a pensar desde este sur global la manera en que producimos conocimiento y damos testimonio de nuestra época.

Este trabajo no constituye una reseña de obras del autor, ni una genealogía de las obras del mismo, sino que recorre tres obras seleccionadas por reunir las principales contribuciones realizadas por Torres Carrillo en la última década. De la obra del 2006 La práctica investigativa en ciencias sociales resaltamos la presentación que hace de la denominada por él investigación de borde o desde las márgenes de las ciencias sociales. En dicha obra se concentra en explicitar el origen y deriva de esta perspectiva. Luego, en el capítulo contenido en la obra de Fernández Moreno et al. (2011), nos amplía los fundamentos de esta opción, mostrando sus aspectos centrales y fuentes de inspiración. Por otro lado, en el artículo de la revista Nómadas del 
año 2014 nos comunica -desde la invitación que le hace la revista- la sistematización de una experiencia organizativa llevada adelante por el colectivo de una cooperativa de Bogotá. También nos comparte un relato autobiográfico muy valioso como ejercicio de autoreflexividad. La centralidad en el sujeto y la subjetividad son nucleares en su pensamiento, en sintonía con los aportes de quienes pregonan una investigación desde abajo y desde el sur, como dice el título de uno de sus libros (Torres Carrillo, 2017).

Respecto de la centralidad del sujeto enunciador y no del enunciado,

Mignolo nos ha enseñado que toda definición implica la determinación de algo y con ello, el control que ejerce el enunciante de aquello definido, siendo que, en clave modernidad/colonialidad, lo que interesa, no es la enunciación sino el sujeto enunciante, de allí la importancia que cobra la geo-corpo-política del conocimiento: quién dice qué, desde dónde, a instancias de qué, con qué intencionalidad, qué lenguas, memorias, tradiciones y saberes se ponen en juego en el acto de la enunciación, qué historias (locales) están involucradas, qué cuerpo habla (Borsani y Quintero, 2014, p. 16, paréntesis en el original).

Próximas a estas aportaciones son las contribuciones del argentino radicado en Colombia Alfredo Ghiso, quien cuenta con vasta experiencia en la sistematización de experiencias e investigación acción participativa (en adelante IAP), y nos orienta sobre cómo incorporar esta propuesta metodológica. Según este autor, siempre que estemos en una actitud dialógica y solidaria, estaremos favoreciendo la construcción colectiva y solidaria de conocimientos que nos permitirán pensar otro horizonte posible.

En la IAP, caracterizada por la reflexividad, la dialogicidad y la solidaridad se recuperan y resignifican construcciones colectivas de conocimiento solidario; esta consciencia permite reconocer y expresar que es posible experienciar otras condiciones de producir conocimientos y discursos sociales. Son condiciones alternativas que posibilitan romper con los fetiches que el sistema tecnocrático hegemónico y globalizado ha ido construyendo, enajenando las capacidades y alienando decisiones de los sujetos, de escoger asuntos de estudio que sean pertinentes y socialmente legítimos (Ghiso, 2016, p. 10).

Como podemos observar la cuestión de la reflexividad es central en este tipo de posicionamiento. Sandoval Álvarez sostiene que ejercer la reflexividad implica advertir la necesidad de reflexionar sobre nuestra práctica situada, y agrega

(...) la reflexividad crítica respecto de la práctica teórica es un punto de partida en la construcción de un pensar epistémico que tenga como centralidad al sujeto (...) exige dar cuenta de cómo salir de la racionalidad que se impone a la realidad en movimiento, es decir, entender que la realidad es producida por el movimiento permanente del sujeto social (Sandoval Álvarez, 2016, p. 25).

En suma, una manera dialógica y solidaria de generar conocimientos, sabiendo que la realidad es producida por los sujetos sociales, es la invitación que nos hacen algunos de los pensadores de la región citados en este trabajo, quienes, aunque nucleados en perspectivas de diferentes denominaciones, entienden que las opciones teórico-metodológicas son también ético-políticas, y desde allí nos convocan a relatar nuestro presente histórico y contribuir a la generación nuevos conocimientos.

Para finalizar esta sección, vale aclarar que este trabajo se inscribe en mi línea de investigación de CIC Conicet cuyo eje es el estudio de la retórica de la modernidad y la lógica de la colonialidad en espacios periféricos del capitalismo global, línea de trabajo que se asienta en la propuesta metodológica de Torres Carrillo junto a la opción decolonial.

\section{Por una inVestigación DeSDe el MARgen}

Respetando un orden cronológico de las producciones de Torres Carrillo reunidas en este escrito, comienzo con la del año 2006. Se trata de un libro compilado por él, que además cuenta con capítulos de su autoría.

Este texto se origina a partir de reflexiones desarrolladas en el marco de un Seminario organizado por la Fundación Universitaria Luis Amigó, en Medellín, Colombia. Recoge la producción del conocimiento social sobre problemáticas, fenómenos y poblaciones emergentes, identificadas como marginales, buscando 
transformar o construir ambientes alternativos potenciando los sujetos y subjetividades individuales o colectivas.

Esta obra busca comunicar características de las prácticas investigativas desde una perspectiva crítica; por tal, comparte reflexiones y estrategias metodológicas desarrolladas por los autores que dan contenido a los diferentes capítulos de este texto. En este sentido, esta obra combina reflexiones teóricas con la praxis investigativa de los diferentes autores. En lo que concierne a los capítulos de Torres Carrillo, este autor se detiene en describir la manera de realizar procesos de recuperación colectiva de historias locales y organizativas apoyadas en educación popular, experiencia que lleva varias décadas de desarrollo en Colombia.

Este texto enfatiza en la idea de que la producción más fructífera de conocimiento no se está gestando desde las universidades, sino más bien desde los márgenes, desde ámbitos no disciplinares y por fuera de las instituciones universitarias. En varias secciones de esta obra se señala que, pese a la riqueza de estos lugares emergentes de investigación que se ocupan de nuevos problemas y actores, caracterizados por la pluralidad teórica y flexibilidad metodológica, se puede desperdiciar su potencial emancipador por no darle un lugar adecuado a la dimensión política en las prácticas investigativas.

Algunas de las explicaciones que se vierten en el texto sobre esta situación tienen que ver con que las ciencias sociales han sido constituidas y constitutivas del proyecto moderno, con lo cual expresan su confianza absoluta en la razón y en el control de la naturaleza.

Como práctica investigativa se realiza tanto desde facultades, departamentos y otros espacios universitarios, así como en espacios no académicos. Es importante señalar que no se asume como disciplinaria y, por lo tanto, la propuesta denominada investigación de borde o desde los márgenes de las ciencias sociales no es reductible a un campo disciplinar. Desde allí entonces, se propone la construcción de objetos de investigación desde un abordaje inter, pluri y transdiciplinar, asumiendo la hibridez conceptual y metodológica como actitud para diferenciarse de las prácticas investigativas ancladas en el proyecto moderno de ciencia.

Desde esta perspectiva se insiste en que todo conocimiento es situado y debe explicitarse el lugar de enunciación. Quien opte por esta propuesta buscará hacer ver lo no visible, nombrar lo no nombrable.

La idea de borde o margen que recorre la obra no significa estar fuera del sistema sino en el borde, en los intersticios. Desde esta posición se prevén miradas y abordajes inéditos que desborden los límites de la ciencia social instituida. Como opción otorga un lugar central al sujeto y a la subjetividad en la investigación social en tanto que es una práctica constructiva, intersubjetiva e intencionada.

"Y porque el conocimiento no es abstracto y des-localizado como nos recuerda Walsh, interesa la ubicación geopolítica del sujeto hablante, ubicación que no sólo refiere al (...) espacio físico, el lugar en el mapa, sino también los espacios histórico, sociales, culturales, discursivos e imaginados" (Walsh, 2002b: 175), espacios culturales que para nuestro caso implican las producciones artísticas en contextos específicos y particulares, como cada una de nuestras comunidades en donde nos desempeñamos (Albán Achinte en Borsani y Quintero, 2014, p. 165, cita y comillas en el original).

Incorpora en su análisis lo cultural, las identidades y las subjetividades colectivas, temáticas que se preguntan por la vida cotidiana.

Los enfoques y metodologías más frecuentes son las cualitativas e interpretativas; los estudios de caso, la etnografía basada en la observación participante, las historias de vida, el análisis de escenarios y acontecimientos concretos y el rescate de la memoria colectiva. Resultan centrales las técnicas participativas y la con-fusión entre los sujetos e investigados.

Uno de los capítulos de Torres Carrillo propone como estrategias metodológicas la investigación acción participativa (en adelante IAP), la sistematización de experiencias de procesos organizativos y la recuperación colectiva de la historia. Sugiere que el saber sobre lo social no es patrimonio exclusivo de la razón científica. Sugiere estar atentos a los nexos entre conocimiento y poder, a las hegemonías y asimetrías que atraviesan lo singular, lo cotidiano, lo narrativo, lo simbólico, etc. Desde esta propuesta se asume que todos pueden 
preguntar y responder, es decir, que todos son portadores y productores de conocimiento. Esa es la idea de sujeto en proceso y de solidaridad en la construcción social del conocimiento.

En suma, esta propuesta es una invitación a investigar desde un paradigma emancipatorio o interpretativo crítico. Por lo tanto, no se agota en la comprensión de los fenómenos, sino que busca intencionalmente intervenir sobre ellos para modificarlos. Reconoce como fuentes de inspiración pensadores colombianos como el reconocido sociólogo Orlando Fals Borda, Alfredo Molano, Rodrigo Parra, Hernán o Rodrigo Parra Sandoval; los antropólogos Hernán Henao, Guillermo Vasco y María Teresa Uribe; Gonzalo Sánchez y Mauricio Archiva. A nivel conceptual, acude a distintas corrientes teóricas y autores, como Geerz, Marc Augé, Touraine, Giddens, Bourdieu, Mafessoli, Foucault, Deleuze, Derrida García Canclini y Martín-Barbero, entre los pensadores latinoamericanos. ${ }^{1}$

En síntesis, como propuesta abraza la pluralidad teórica y flexibilidad metodológica investigando sobre problemas transversales.

\section{LA CENTRALIDAD EN EL SUJETO}

De la producción del año 2011 de Torres Carrillo se recupera la reflexión que realiza sobre los obstáculos que debieron enfrentar los procesos de investigación de las ciencias sociales en América Latina por haber sido colonizada intelectualmente. Desde el siglo XVII los científicos sociales se abrogaron el monopolio de la producción de conocimiento sobre lo social. Las ciencias sociales clásicas estuvieron dominadas por un paradigma positivista que separó el sujeto de conocimiento de la realidad social que investiga, pasando por alto la necesaria conexión entre la comprensión y la crítica al orden hegemónico global y la consecuente construcción de alternativas.

Como obstáculos menciona los supuestos positivistas de universalidad, objetividad, determinismo, reduccionismo y monismo metodológico; así como la arbitrariedad de las fronteras disciplinares dentro de las ciencias sociales y humanidades y la imparcialidad y neutralidad de la actividad científica. Estas rupturas implicaron múltiples desplazamientos y rechazos a nivel pedagógico, metodológico y político-académico, en el pasaje de la década del 60 al 70 del siglo XX, como lo explica Lander, cuando las sociedades exploraron interpretaciones que iban a contracorriente de las concepciones dominantes sobre el continente, apostando a otras modalidades del conocer y a otras nociones del sujeto y de la relación objeto/sujeto en el proceso del conocimiento.

Tres ejemplos son suficientes para ilustrar esta rica herencia. El pensamiento político-académico de las décadas de los 60 y los 70 -época de efervescencia de las luchas populares en todo el continente y de los debates sobre la dependencia- si bien no logró desprenderse del imaginario (colonial) del desarrollo, significó no sólo rupturas sustanciales en el rechazo a las particiones dogmáticas que estableció la tradición liberal entre los diferentes ámbitos de lo histórico-social (lo político, lo social, lo económico, lo cultural), sino que igualmente trasgredió expresamente las exigencias de objetividad de una ciencia social que pretendía ser valorativamente neutra, al asumir la producción de conocimiento sobre lo social como una toma de partido, como parte de un compromiso político de transformación social. Desde el punto de vista metodológico la investigación-acción, o investigación militante, que tiene como máxima expresión el trabajo teórico-práctico de Orlando Fals Borda y sus colaboradores. Rechazando las pretensiones objetivistas del método científico, proponen la investigación como instrumento de transformación y la práctica de la transformación social como vía privilegiada del conocimiento de lo histórico-social. La pedagogía del oprimido de Paulo Freire expresa esa misma ruptura en el campo pedagógico. Rechazando - por conservadora y reproductora de las relaciones sociales jerárquicas existentes- el que el maestro sea poseedor de un conocimiento que deba llevar (con el cual deba "llenar") al educando, Freire propone metodologías de aprendizaje activo, a partir de las propias prácticas y vivencias. El proceso del conocer es concebido como creación de conocimiento, como una dinámica de autoconciencia -individual y colectiva - que permita reconocer las relaciones de opresión y facilitar la liberación (Lander, 2001, paréntesis en el original; el resaltado es propio).

Próximo a este pensamiento, Mignolo invita desde el pensar decolonial a hacer una crítica al paradigma europeo de la racionalidad/modernidad. Lo considera indispensable para realizar desprendimientos de las 
formas normativas de control del conocimiento científico, que en sus variedades sociales y naturales resultan formas de hacer y conocer orientadas al objeto y no al sujeto, al enunciado y no al enunciador.

La opción de-colonial se vuelca hacia el sujeto enunciante; se desprende de la fe en que el conocimiento válido es aquel que se sujeta a las normas disciplinarias, esto es, al conocimiento por gestión empresarial mediante las reglas impuestas por el grupo de seres humanos que aceptan jugar ese juego (Mignolo, 2008, p. 247).

La centralidad en el sujeto es también explicitada en la obra de Sandoval Álvarez, para quien "dar lugar a una metodología de la investigación en la perspectiva del sujeto, implica, en principio, saberse situado desde una postura ética y política (...) y enfrentar los desafíos de un mundo donde se reconozca la intersubjetividad (...)" (Sandoval Álvarez, 2016, p. 26). Esto va de la mano con lo que nos recuerda Torres Carrillo, para quien "el saber sobre la realidad sociohistórica no es patrimonio exclusivo de las disciplinas sociales; forma parte de otras prácticas culturales como la literatura, el cine, el teatro..." (Torres Carrillo, 2011, p. 27).

Desde estas ideas, Torres Carrillo caracteriza a la producción de conocimientos en base a los siguientes criterios:

- el rescate del sujeto y lo subjetivo;

- la confusión entre el investigador y los sujetos investigados;

- el "recuperar la memoria colectiva, comprender prácticas, contextos y actores sociales o develar ideologías y prácticas dominantes" (Torres Carrillo, 2011, p. 29);

- valorar la posibilidad de producir saber sobre lo social desde otras prácticas intelectuales como los movimientos sociales y las luchas culturales y étnicas (Torres Carrillo, 2011, p. 29).

Como podemos observar los puntos de encuentro con los pensadores decoloniales citados en este trabajo son frecuentes, siendo quizás el rescate del sujeto y lo subjetivo el aspecto de mayor encuentro. En relación a ello, enfatiza en la idea de que "lo que le da el carácter de potencialidad a las prácticas investigativas de borde no son sus actores, lugar institucional, perspectivas conceptuales o estrategias metodológicas, sino su intencionalidad y sentido político" (Torres Carrillo, 2011, p. 43).

Recapitulando lo expresado hasta aquí, ¿qué es investigar desde los márgenes?

Torres Carrillo argumenta que la investigación de borde o desde los márgenes es ante todo un posicionamiento ético y político y una práctica de producción del conocimiento llevada a cabo por sujetos individuales o colectivos que, proviniendo de las Ciencias Sociales o no, transgreden la racionalidad disciplinar dominante. Próxima a esta denominación, encontramos otras como "epistemología fronteriza (Mignolo); pensamiento del umbral (Zemelman); nomadismo intelectual (Maffesoli); perspectiva de borde; razonamiento de umbral” (Torres Carrillo, 2011, p. 31). Así, las problemáticas investigadas desde los márgenes guardan relación con problemáticas como la migración, la violencia, el desplazamiento forzado, las juventudes y las culturas urbanas.

A nivel terminológico, los conceptos que estructuran la discusión en esta opción son los términos marginal o liminal. Lo marginal no es estar fuera, sino en el umbral, en las fronteras, entre el adentro y el afuera, entre lo instituido y lo instituyente, entre lo conocido y lo inédito. Abre nuevas posibilidades para pensar, imaginar, leer y construir la realidad social. Pone en evidencia los límites y las arbitrariedades del orden social.

Para finalizar, vale insistir que potenciar la investigación de borde requiere una mayor conceptualización y elaboración epistemológica que dé cuenta de nuevas búsquedas en la actividad investigativa.

\section{LOS ONCE RASGOS QUE DEFINEN ESTA OPCIÓN}

Del artículo contenido en la revista Nómadas (2014) interesa la descripción de los rasgos elaborados por el autor que caracterizan a esta opción. También es de resaltar la manera de presentarse del autor, a través de un relato autobiográfico, enseñando y provocando al lector a hacerlo a su vez. Su relato comienza así: 
A la luz de esta sentencia del nobel colombiano, intentaré hacer un relato de los procesos y de los hitos significativos que permitieron formarme de una manera particular como investigador social comprometido con procesos organizativos populares y acciones colectivas orientadas por visiones de futuro alternativas frente al orden social dominante. Sin ningún ánimo narcisista, a continuación intentaré reconstruir aquellos contextos y hechos, que a lo largo de mi trayectoria vital, han condicionado e incidido en mi formación investigativa.

Nací en Bogotá a comienzos de la década de los años sesenta en el seno de una familia trabajadora; mi padre era un ebanista, autodidacta y librepensador; mi madre, una ama de casa quien, además, realizaba manualidades para completar los ingresos familiares. El primero había sido "chino bogotano" en la década del veinte, aprendiz de varios oficios antes de convertirse en ebanista en la década siguiente, participó en asociaciones sindicales y en el movimiento gaitanista durante la década de los cuarenta, antes de emplearse como obrero de Sears Roebuk durante las tres décadas siguientes (Torres Carrillo, 2014, p. 70, comillas en el original).

Como ejercicio de reflexividad nos acerca una manera de presentarnos, nombrarnos, posicionarnos que resulta un ejercicio interesante y necesario de autoreflexividad. Esta manera de explicitar su trayectoria y situarse ante las problemáticas que estudia es un reto para los investigadores, quienes, en general, sólo explicitan los autores y marcos teóricos que estructuran un trabajo. También a partir de esa manera de presentarnos damos testimonio de nuestra época y relatamos nuestro presente, respondiendo a los interrogantes de Guarín Jurado con el que iniciaba este artículo.

Como anticipé, en este artículo Torres Carrillo se detiene en relatar su experiencia de co-construcción de conocimientos. El conocimiento colectivo y solidario fue desarrollado con un colectivo nucleado en una cooperativa de vivienda de Bogotá: AVESOL. En el ejercicio de su praxis investigativa define los once rasgos que caracterizan las metodologías críticas cualitativas, antes denominadas de borde o desde los márgenes de las ciencias sociales, como más adelante explicitaré.

Esta modalidad de producción de conocimiento se caracteriza por ser intencionada, colaborativa y solidaria. Para iniciarse en esa práctica propone acciones tales como formar un equipo de investigación con el colectivo de trabajo, definiendo con ellos las preguntas/problemáticas a abordar, así como la asignación de roles y responsabilidades para encarar conjuntamente la reconstrucción descriptiva y narrativa de la experiencia en un proceso de organización social, como lo detalla en el artículo de referencia.

De las estrategias mencionadas anteriormente, la sistematización de experiencias fue la llevada a cabo en este caso. A través de ella realizaron una reconstrucción temporal y una periodización del proceso que dio origen a la cooperativa, y luego iniciaron el análisis e interpretación de la lógica y sentidos que se construyeron socialmente en torno a la organización de la cooperativa. Esa es la experiencia sistematizada que se comunica en el número de la revista Nómadas. Finalmente, la síntesis, socialización y comunicación de los resultados también se realiza de manera colectiva y solidaria.

En esa sistematización de la experiencia, el autor fue describiendo los once rasgos por él definidos que caracterizan a las metodologías críticas cualitativas:

1. Una producción de conocimiento que toma distancia crítica de los modos de investigación institucionalizados en el mundo científico.

2. Una producción de conocimiento que se asume como crítica y emancipadora.

3. Una práctica investigativa "localizada".

4. Una producción de conocimiento articulada a procesos organizativos y a dinámicas de acción colectiva emancipadores.

5. Una producción de conocimiento "nómada" o "liminal" que no se define ni se subordina a la lógica institucional de la investigación disciplinar.

6. Una producción de conocimiento colectiva que promueve la "participación” de los colectivos y organizaciones en las decisiones del proceso investigativo.

7. Una práctica investigativa que propicia la formación de colectivos de conocimiento.

8. Una propuesta investigativa que se relaciona críticamente con la teoría.

9. Una práctica de producción de conocimiento que promueve el “diálogo de saberes”. 
10. Una producción de conocimiento que asume lo metodológico como una práctica flexible.

11. Una práctica de producción de conocimiento reflexiva (Torres Carrillo, 2014, pp. 73-76).

En suma, la producción intencionada y colectiva de conocimientos reconoce la complejidad de las prácticas objeto de sistematización.

A modo de cierre, y como síntesis: esta propuesta denominada investigación de borde como opción metodológica, desarrollada por el investigador social y educador popular colombiano Alfonso Torres Carrillo, es entendida como

cierto modo de asumir, entender y practicar la producción de conocimiento que en otros momentos he nombrado y conceptualizado como "investigación interpretativa crítica" (Torres, 1996 y 1997, "investigación crítica" (2000), “investigación cualitativa crítica” (Torres, 2003) e "Investigación desde el margen” (Torres, 2004 y 2008). Dicho enfoque -que se sitúa en la tradición crítica iniciada por Freire y Fals Borda- asume la investigación como una práctica colectiva de producción de conocimiento, articulada a procesos organizativos y movimientos sociales, que se propone, comprender y fortalecer su capacidad de resistencia y generación de alternativas al capitalismo, así como contribuir a la producción de subjetividades y a la transformación de realidades y sujetos desde una perspectiva crítica y emancipadora (Torres Carrillo, 2017, p. 5).

Luego de lo expuesto, mantuve la denominación investigación de borde, aunque también reciba otras denominaciones, considerando que lo relevante no es la denominación en sí, sino la experiencia de sentirse en los bordes. A continuación expondré algunas reflexiones acerca de cómo en el equipo de investigación bajo mi dirección nos sentimos afectados por esta perspectiva y atravesados por la experiencia de borde.

\section{AfECTADOS POR LA EXPERIENCIA DE BORDE}

En esta sección recupero las reflexiones del segundo encuentro realizado en el marco del equipo de investigación bajo mi dirección titulado "Investigación de borde y decolonialidad: ejes para construcción de conocimientos desde los márgenes de las ciencias sociales. Hacia la formación de un semillero de investigación". ${ }^{2}$

Previo a ese encuentro cada integrante había leído las tres obras a las que se refirió en este trabajo, y desde ellas debíamos pensar: ¿Cómo nos impacta, e involucra esta perspectiva? ¿En qué casos estamos experimentando, sentimos que podemos/deseamos construir conocimientos desde esta perspectiva? ¿Qué limitaciones reconocemos para desarrollar una investigación desde el margen o borde?

Esto nos llevó a conversar sobre una serie de cuestiones operativas inherentes a la investigación de borde, como la manera en que usamos los datos, las teorías, de dónde y cómo ocurre la socialización del conocimiento, así como las posibilidades y limitaciones que reconocemos para pensarnos investigando de la manera en que nos sugiere Torres Carrillo, otorgando centralidad al sujeto desde una perspectiva crítica, participativa, desplazando la objetividad y dando lugar a la reflexividad. En la primer parte de la reunión, cada uno de los integrantes presentes expresó lo que le había generado la lectura de este autor.

Los profesores compartimos la vivencia de "sentirnos de borde", y este sentir nos pone en sintonía con el tratamiento de ciertos temas y generamos empatía con ciertas áreas del conocimiento. En consonancia con esto, nos definíamos como una comunidad de hablantes antes que como equipo de investigación. Recuerdo aquí un compañero de otro equipo de investigación que decía "de estos temas no se vuelve”, en el sentido de que cuando uno accede a estas miradas y se siente identificado, no las abandona, no se puede salir de ellas.

Cada uno de los integrantes fue expresando su experiencia de borde. Javier, contador y psicólogo social, recordó que pudo acceder a un cargo universitario en una carrera que nada tiene ver con los números, sino con lo social. Su doble titulación le permitió concursar un cargo docente en la carrera de Psicopedagogía. En su exposición expresó ser el más "de borde" del equipo, refiriéndose a que su título es una Tecnicatura 
que les recorta el campo de acción, cuando tienen capacidad de intervenir en equipos interdisciplinarios sin solaparse con los psicólogos. Esa falta de reconocimiento lo ubica ahí.

Luego Natalia, Licenciada en Educación y Educadora Popular, también expresó la situación de borde que experimenta la Pedagogía en el campo de las ciencias sociales (título que no se otorga porque se otorga el de Licenciado en Ciencias de la Educación) relatando vivencias de menosprecio y/o descalificación de la profesión, situación que se institucionaliza en el caso de la Universidad donde trabaja (Universidad Nacional de la Patagonia Austral).

Por el lado de la geografía, las alumnas Yanina y Celeste expresaron estar conociendo estos textos y en todo caso sentir que transitan en el medio entre lo que sería una manera de investigar más tradicional y estas aportaciones. Celeste dijo "los geógrafos sabemos un poco de todo y nada de mucho", dando cuenta del perfil que en muchos currículums todavía tiene la geografía y su pretensión de saber integrador.

Por mi parte compartí que siento haber avanzado hacia saberes transdiciplinares y que mi mirar-razonar es cada vez menos disciplinar y cada vez más producto de una sedimentación de sentidos, conocimientos, experiencias. Con cierta trayectoria puedo hacer esta lectura y desprenderme de ciertos prejuicios que acarrean algunas disciplinas.

Otro de los momentos interesantes del intercambio resultó cuando Javier expresó, refiriéndose a las catalogaciones o rótulos que a veces recibimos, que la estrategia es no asumir ese rótulo. Esto vino a raíz de que ciertas formaciones profesionales parecen ser las autorizadas a hablar de ciertos temas y, de los que estábamos presentes, ninguno pertenecía a esas prestigiosas carreras.

En este encuentro llegamos a la conclusión de que no parece haber retorno o vuelta atrás luego de conocer y verse impactado y atravesado por esta opción.

En lo personal el acercamiento a las lecturas me generó la necesidad de hallar y exponer nuevos lugares de enunciación, algo nuevo para mí hasta la lectura del texto que contiene el artículo de Torres Carrillo (2011, en Fernández Moreno et al.), obra que conocí por gentileza de una de sus autoras. A partir de este texto comencé a reflexionar sobre mi propia práctica investigativa. También me significó leer por primera vez un texto relatado como un conversatorio, inspirándome nuevas maneras de comunicar. ${ }^{i}$

\section{Desobediencia ACADÉmica}

Incorporo bajo este título impresiones y expresiones personales que hacen al proceso de construcción del conocimiento y a las nuevas formas de comunicación. Sin embargo, las mismas fueron criticadas cuando una versión anterior de este escrito fue enviado a una revista para su evaluación. El trabajo resultó aprobado con modificaciones, y muchas de ellas tenían que ver con estas impresiones, con la manera de comunicar. En consecuencia, por no compartir en su mayoría las observaciones del evaluador, desestimé la publicación en dicha revista avisando que cedía mi espacio para otra publicación.

Sólo incorporo en este segmento una de las observaciones: "deja mucho protagonismo a las impresiones personales que suscita en el autor, y en algunos de sus colegas, sin concentrarse en lo que en realidad debería concentrarse: en la exposición rigurosa y ordenada de esas ideas que considera originales" (evaluador, cursiva en el original).

En respuesta, Fischetti y Chiavazza (en De Oto y Alvarado, 2017) nos invitan a escribir narrativamente e incluso autobiográficamente y producir un texto desrigidizado. Nos invitan a transgredir los límites académicos. Todo esto abona al conocimiento desde el margen y al conocimiento situado. De allí la discrepancia con el evaluador.

La perspectiva de borde es de carácter crítico en sentido amplio (y no por tener como referente a la teoría crítica), tiene entre sus pretensiones luchar contras las herencias coloniales que operan a nivel epistémico, implicando los desplazamientos señalados en este artículo y otras maneras de comunicar, razonar, emocionarse. 
Por lo tanto, desde estas perspectivas es oportuno y necesario incorporar nuevas maneras de comunicar y explicitar lo que le da sentido a nuestras investigaciones, recordando que no somos sólo sujetos cognoscentes sino también sentipensantes. En consecuencia, otorgo lugar en esta publicación a la manera en que me he vinculado con estos materiales y autores, aunque esas impresiones personales hayan sido evaluadas como carentes de interés. No es un tema secundario para quienes adscribimos a estas perspectivas explicitar esto también.

En mi experiencia, a partir de tomar conocimiento de la obra de Torres Carrillo, y al conocer a partir de él a pensadores de la talla de Fals Bolda y Zemelman, inicié una serie de lecturas y procuré encarar mi praxis investigativa desde esta perspectiva (además de promocionarla a través del dictado de seminarios y talleres). Como señalé anteriormente, esta perspectiva, como dice su precursor, potencia la creatividad y brinda mayor flexibilidad a la forma de investigar, a lo nuevo, a las nuevas relaciones, a generar nuevos conocimientos.

Dicho esto considero estar iniciando una trayectoria en este sendero, realizando algunos esfuerzos o ejercicios tendientes a generar un mirar por lo menos novedoso, e incidir en las disciplinas académicas con las que estoy vinculada desde la docencia. Posicionarme en la investigación de borde significa no sólo pensarla, difundirla, sino desplazar la centralidad del investigador hacia el sujeto investigado, reconociendo la necesidad de avanzar hacia explicaciones más holísticas desde nuevos aportes transdisciplinares.

Respecto a lo que nos preguntábamos en el equipo acerca de las limitaciones que reconocemos para desarrollar una investigación desde el margen o borde, en lo personal, reconozco limitaciones en la co-labor del conocimiento por falta de experiencia en lo que respecta al trabajo con colectivos. A raíz de esto, le consulté por mail a Torres Carrillo cuán posible consideraba encarar una co-construcción de conocimientos desde esta perspectiva, aunque no trabaje con una organización social, a lo que respondió:

Me siento muy honrado de saber que otros colegas estén haciendo algo con mis ideas; siempre la puesta en práctica de un principio o criterio metodológico, lo desborda y lo enriquece; tanto lo decolonial, como lo crítico y lo liminal son más que posiciones epistemológicas, son actitudes éticas y políticas abiertas, flexibles, que pueden crecer en las práctica investigativa. Así que toda iniciativa creativa aporta. Leeré tu interesante artículo y continuamos la conversación (Torres Carrillo, comunicación personal, 5 de abril de 2017, extracto de mail).

Nuevamente, recuperando a Fischetti y Chiavazza (en De Oto y Alvarado, 2017), quise cerrar este segmento con estas apreciaciones personales respondiendo a la invitación de los autores arriba citados a narrar lo que da sentido a nuestras producciones. De allí las líneas compartidas.

\section{Conclusiones}

A partir del tema y autor seleccionado para esta comunicación pretendí instalar nuevas temáticas y cuestiones de índole metodológica para dar un vuelco a nuestras investigaciones posicionadas en la racionalidad dominante. No se trata de dejar de hacer ciencia, sino hacerla de otra manera, de generar conocimiento de otro modo como nos decía Arturo Escobar (2003), lo que implica posicionarnos en el sujeto, la subjetividad, la reflexividad, a la vez que construir y comunicar de manera también diferente los resultados.

Los aportes que nos deja la investigación crítica y participativa amplían la perspectiva y el horizonte crítico de nuestras investigaciones. Deseo que el recorrido por estos textos provoque nuevas búsquedas y el tránsito hacia el giro dialógico desde donde se proponen nuevos criterios de validación del conocimiento. Así llegamos al final de este escrito, cuya finalidad fue posicionar la investigación de borde. 


\section{REFERENCIAS}

Albán, A. (2014). Arte, docencia e investigación. En M. E. Borsani y P. Quintero (Comp.), Los desafios decoloniales de nuestros dias: pensar en colectivo. (151-172) Neuquén: EDUCO-Universidad Nacional del Comahue. Recuperado de http://www.ceapedi.com.ar/imagenes/biblioteca/libreria/332.pdf

Borsani, M. E. y Quintero, P. (Comp.) (2014). Los desafios decoloniales de nuestros días: pensar en colectivo. Recuperado de http://www.ceapedi.com.ar/imagenes/biblioteca/libreria/332.pdf

De Oto, A. y Alvarado, M. (Eds.) (2017). Metodologías en contexto: intervenciones en perspectiva feminista, poscolonial, latinoamericana. Recuperado de http://biblioteca.clacso.edu.ar/clacso/se/20180209122042/Metodologias_en _contexto.pdf

Escobar, A. (2003). Mundos y conocimiento de otro modo. Tabula Rasa, 1, 51-86. Recuperado de http://www.revi statabularasa.org/numero-1/escobar.pdf

Fischetti, N. y Chiavazza, P. (2017). Narrativas. Arte y ciencia en los márgenes de la academia. En A. De Oto y M. Alvarado (Eds.), Metodologias en contexto: intervenciones en perspectiva feminista, poscolonial, latinoamericana (126-145). Recuperado de http://biblioteca.clacso.edu.ar/clacso/se/20180209122042/Metodologias_en_cont exto.pdf

Ghiso, A. (1999). Acercamientos: el taller en procesos de investigación interactivos. Estudios sobre las Culturas Contemporáneas, 5(9), 141-153. Recuperado de https://www.redalyc.org/articulo.oa?id=31600907.

Ghiso, A. (2016). Diálogo y participación como generadores de saberes (Reflexionar la educación popular y la IAP desde la experiencia). Recuperado de https://www.academia.edu/28463498/DI\%C3\%81LOGO_Y_PARTICIPACI\% C3\%93N_COMO_GENERADORES_DE_SABERES_Reflexionar_la_educaci\%C3\%B3n_popular_y_la_I AP_desde_la_experiencia

Guarín Jurado, G. (2017). Desplazamientos epistemológicos contemporáneos en las ciencias sociales y humanas en América Latina. En S. V. Alvarado, E. Rueda y G. Orozco (Eds.), Las ciencias sociales en sus desplazamientos (28-38). Buenos Aires: CLACSO. Recuperado de http://biblioteca.clacso.edu.ar/clacso/se/20171030020245/ Las_ciencias_sociales_en_sus_desplazamientos.pdf

Lander, E. (2001). Pensamiento crítico latinoamericano: la impugnación del eurocentrismo. Recuperado de http://ww w.ceapedi.com.ar/imagenes/biblioteca/libreria/89.pdf

Mignolo. W. (2008). La opción de-colonial: desprendimiento y apertura. Un manifiesto y un caso. Tabula Rasa, 8, 243-281. Recuperado de http://www.revistatabularasa.org/numero-8/mignolo1.pdf

Sandoval Álvarez, R. (2016). Cuaderno I: formas de hacer metodología en la investigación. Reflexividad crítica sobre la práctica. Guadalajara: Grietas editores. Recuperado de https://www.academia.edu/32890362/Rafael_Sandova 1_Formas_de_hacer_metodologia.pdf

Torres Carrillo, A. (2006). Por una investigación desde el margen. En A. Jiménez Becerra y A. Torres Carrillo (Comp.), La práctica investigativa en ciencias sociales. (62-79) DCS, Departamento de Ciencias Sociales. UPN, Bogotá: Universidad Pedagógica Nacional. Recuperado de http://bibliotecavirtual.clacso.org.ar/ar/libros/colombia/dc supn/practica.pdf

Torres Carrillo, A. (2011). Investigar desde los márgenes de las ciencias sociales. En S. Fernández Moreno, M. Gómez Builes y M. López Muñoz (Comp.), Conversaciones sobre las prácticas investigativas desde la pregunta por las metodologías criticas en contextos sociales de despojo, destierro y desplazamiento forzado: elementos provocadores para una filosofia de la praxis (25-45) Medellín: Universidad de Antioquia, Medellín.

Torres Carrillo, A. (2014). Producción de conocimiento desde la investigación crítica. Nómadas, 40, 68-83. Recuperado de http://nomadas.ucentral.edu.co/index.php/inicio/9-problemas-sociales-contemporaneos-nom adas-40/52-produccion-de-conocimiento-desde-la-investigacion-critica

Torres Carrillo, A. (2017). Producción de conocimiento desde la investigación crítica. Bogotá: Universidad Pedagógica Nacional. Cátedra Doctoral 2017- 1 Cátedra Inaugural. Inédito. ${ }^{3}$

Torres Carrillo, A. (2017). Hacer historia desde Abajo y desde el Sur. Bogotá: Planeta Paz-Ediciones desde abajo. 
Revista latinoamericana de Metodología de las Ciencias Sociales, 2020, 10(1), Junio-Noviembre, ISS...

\section{Notas}

1 Estos autores son citados por Torres Carrillo, sin explicitar las contribuciones o relaciones entre sus propuestas y la perspectiva de borde.

2 Acreditado por Secyp-UNPA 29/A374-1 Proyecto tipo 1 - Investigación y desarrollo. Unidad ejecutora: UNPAUARG. Instituto de Trabajo, Economía y Territorio. Fecha inicio: 2016/finalización: 2017.

3 Acceso al texto por gentileza del autor.

i Felizmente, luego de una serie de intercambiamos por mails, en 2017 conocí a Torres Carrillo con motivo de un viaje que realicé a su país por un congreso.

\section{BY-NC-SA}

